\title{
Filariasis serosurvey, New Caledonia, South Pacific, 2013
}

Maguy Daures ${ }^{1 *}$, Julie Champagnat ${ }^{1}$, Anne Pfannstiel ${ }^{1}$, Frédérique Ringuenoire ${ }^{1}$, Jean-Paul Grangeon ${ }^{1}$ and Didier Musso ${ }^{2}$

\begin{abstract}
Background: Lymphatic filariasis (LF) is a major public health problem in the Pacific. As the global prevalence of infection was not known in New Caledonia (NC), a serosurvey study was conducted by determining the prevalence of circulating filarial antigens, as recommended by the World Health Organization.

Findings: A cross sectional study on a 2 degree stratified sample was carried out from June to November 2013. Inclusion criteria were: individuals aged 2 to $80 \mathrm{y} / \mathrm{o}$, who had been hospitalized or sought medical care for a non-infectious cause and who had been living in NC for more than 6 months. LF antigenic detection was performed using the immunocromatographic BinaxNOW filariasis card test (ICT).

Among the 1,035 individuals tested, 7 were antigenic. The overall LF antigenic prevalence was 0.62\% (Cl 95\% [0.60-0.63]). All patients were unrelated to each other; none of them presented clinical symptoms of LF.

Four of the 7 ICT positive patients reported having travelled to LF endemic areas, 2 patients had never traveled outside $\mathrm{NC}$ and the last one had only traveled in non-endemic areas.

For the 7 ICT positive patients, the research of microfilariae in blood smears and filarial DNA by PCR was negative.

Conclusion: The prevalence of filarial antigenemia in NC is less than 1\%, the threshold that defines the filarial endemic areas for WHO. Nevertheless, as two patients who had never travelled outside NC and one who had only travelled to non-endemic areas were antigenic, we cannot conclude that NC is totally free of LF.
\end{abstract}

Keywords: Lymphatic filariasis, Serosurvey, New-Caledonia, Pacific

\section{Background}

Lymphatic Filariasis (LF) is transmitted by mosquitoes and caused by three species of nematodes but only Wuchereria bancrofti is found in the Pacific area [1-3]. Filariasis, is common in many parts of the tropics and subtropics, including Pacific island countries and territories (PICTs). This neglected tropical disease is a major cause of disability, social stigmatization and reduced economic life opportunities [4,5]. In 1997, the World Health Organization (WHO) declared LF to be one of six potentially eradicable diseases, and the Global Programme to Eliminate Lymphatic Filariasis (GPELF) was then established with the goal of the "elimination of LF as a public health problem by the year $2020[6,7]$ ”.

\footnotetext{
* Correspondence: maguy.daures@gmail.com

${ }^{1}$ Health Action Service, New Caledonia Health Department, BP N4 - 98851

Nouméa cédex, New Caledonia

Full list of author information is available at the end of the article
}

New Caledonia (NC) is a French Territory located in the Southwest Pacific Ocean. It is one of the 22 PICTs comprising 250.000 inhabitants $(40.3 \%$ Melanesian, $34.6 \%$ European, 9.3 mixed-race, 8.7\% Wallisian, 2.0\% Tahitian, a few Asian and Vanuatuan, and 5.1\% indeterminate).

Historically, the levels of filariasis in the Pacific area have been some of the highest in the world [3]. In 1999, the Pacific Programme to Eliminate Lymphatic Filariasis (PacELF) was created [8] and most of the PICTs, but not $\mathrm{NC}$, conducted initial surveys to map the extent of LF.

As elephantiasis was not being diagnosed in $\mathrm{NC}$ and Aedes polynesiensis, the main vector of LF in the Pacific region was not present [9], it was assumed that the overall prevalence of LF would be low. Nevertheless, since French Polynesia (FP) is still a high endemic area for LF [10] and this ethnic group accounts for $2.0 \%$ of the NC population with routine travel exchanges between the two countries, we cannot exclude the possibility that LF is endemic in $\mathrm{NC}$, especially in some remote areas such 
as Ouvea Island or villages on the northeast coast of New Caledonia, where LF cases have been reported in the past (Canala, Pouebo, Ouega) [11,12].

In order to evaluate NC's status in regards to LF, we conducted a serosurvey study by determining the prevalence of circulating filarial antigens (CFA) using immunochromatographic card tests (ICT), as recommended by the WHO [13].

\section{Methods}

The serosurvey study was conducted from June to November 2013. A cross sectional study on a 2 degree stratified sample was implemented. Inclusion criteria were: individuals aged 2 to $80 \mathrm{y} / \mathrm{o}$, who had been hospitalized or had sought medical care for a non-infectious cause (temperature below $37.5^{\circ} \mathrm{C}$ ) and who had been living in $\mathrm{NC}$ from more than 6 months.

Ethical approval was obtained by the People Protection Committee South-west and Overseas III, Bordeaux, France under reference 13.269. Informed written consent was obtained from all participants for medical interview and blood samples.
The sample size was calculated for a cross sectional study with consideration of the sample plan (design effect) $[14,15]$. A total of 1,321 individuals were to be included in the study for a seroprevalence precision of $+/-4 \%$ (a refusal rate of $10 \%$ was planned).

Sampling design: NC was first stratified in 5 areas [Noumea has 39.7\% inhabitants of NC, the greater Noumea area (26.9\%), East Coast (12.9\%), West Coast (13.4\%) and Loyalty Islands (7.1\%)]. At the first stage, a randomized selection of medical centers and GPs was made. At the second stage, eligible individuals were included in the study by systematic sampling.

Data on socio-demographic characteristics and history of travel were collected using a standardized questionnaire. A blood sample was collected by venous puncture at the end of the interview. For children under the age of $10 \mathrm{y} / \mathrm{o}$, antigenic detection was performed only on blood samples collected for other reasons.

After collection, samples were stored and then shipped at $-20^{\circ} \mathrm{C}$ to the Louis Malarde Institute in Tahiti (FP) where they were stored at $-20^{\circ} \mathrm{C}$ until processing.

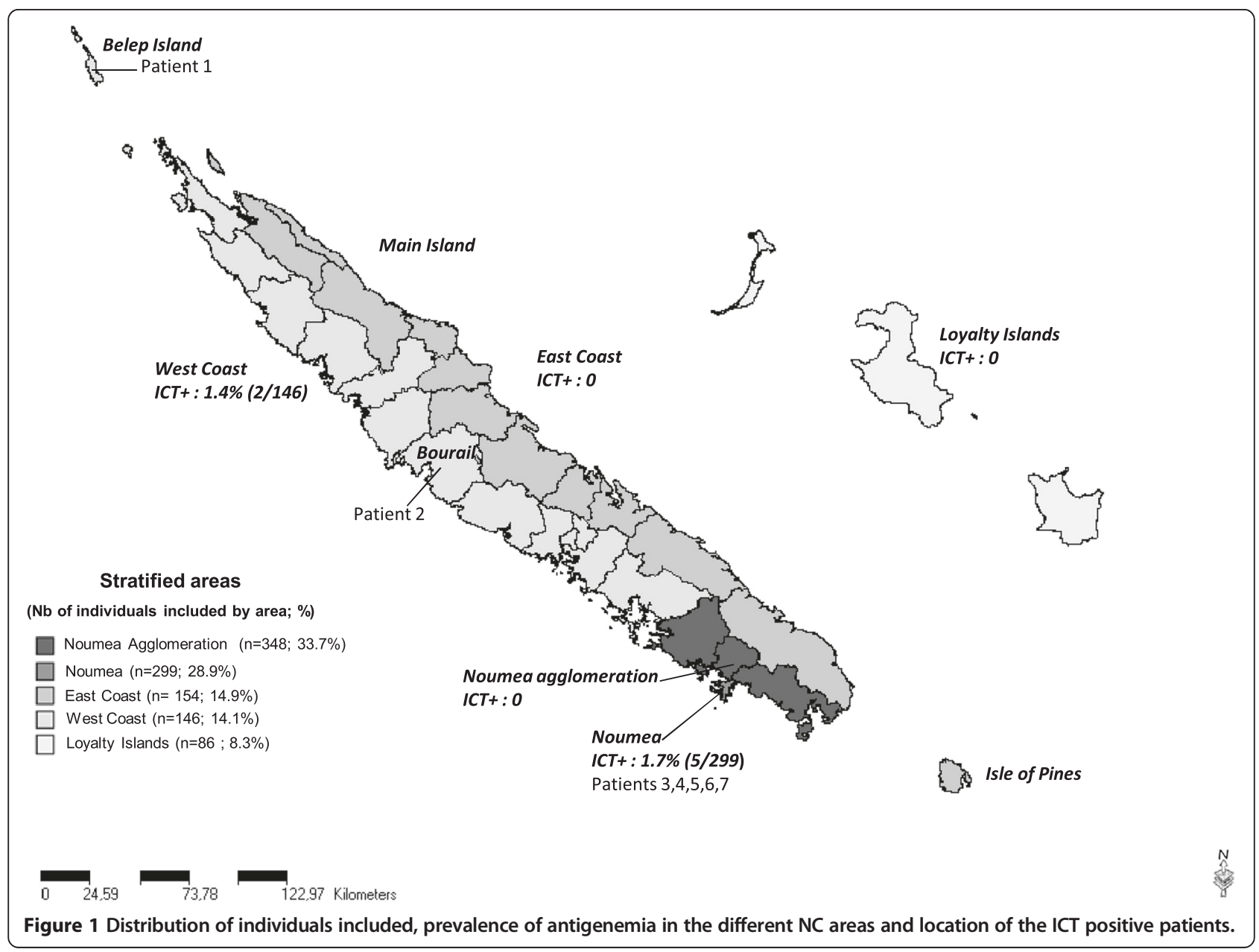


LF antigenic detection was performed using the immunocromatographic BinaxNOW filariasis test (Alere North America, Orlando, USA) (Inverness Medical) following the manufacturer's instruction. In order to avoid false positive reactions the results were recorded 10 minutes after specimen application [16].

After antigenic testing results were obtained, all antigenpositive individuals were contacted and examined by a medical practitioner from the New Caledonia Health Department in order to detect any clinical symptoms of LF. A second blood sample was taken for microscopic and molecular filarial detection. For molecular detection of filarial DNA [17], whole blood was spotted on filter paper and sent to the Louis Malarde Institute in Tahiti FP for individual molecular detection by polymerase chain reaction, as previously described [18].

The data were analyzed using STATA 12.1 software. Data were adjusted by sex, estimates and confidence intervals (CI) were calculated using the "survey" command to consider the sampling plan. The prevalence and 95\% CI of filariasis standardized by age was estimated based on the WHO world reference population.

\section{Findings}

A total of 1035 individuals were included in the study. Melanesians were over-represented (48.3\%) and Europeans underrepresented $(22.9 \%)$ in the sample compared to the general population $(\mathrm{p}<0.0001)$.

The overall LF antigenic prevalence (after considering the sample plan) was $0.62 \%$ (CI 95\% [0.60-0.63]). The
ICT filariasis test was positive for 7 patients. Prevalence of antigenemia in the different $\mathrm{NC}$ areas and locations of the ICT positive patients is shown in Figure 1.

For the 7 ICT positive, all the data recorded through the medical questionnaire and their laboratory data are given in Table 1 . The median age of those patients was $35 \mathrm{y} / \mathrm{o}$ (ranging from 28 to $64 \mathrm{y} / \mathrm{o}$ ), the sex ratio (F/M) was 1.33, 5 lived in Noumea, 1 in Belep Islands and 1 in a village on the West Coast. Two were Melanesians and five were Europeans, none of them were from the Tahitian population living in NC. All patients were unrelated to each other; none of them showed any clinical symptoms of LF.

Four of the 7 ICT positive patients reported having travelled in the past in an LF endemic country (Vanuatu, FP, Indonesia, Viet Nam, Malaysia and Sri Lanka), 2 had never traveled outside NC to an LF endemic country [19].

For the 7 ICT positive patients tested for live microfilariae and filarial DNA were negative.

Each ICT positive patient received treatment consisting of a single dose of albendazole (400 mg) and diethyl carbamazine (400 mg).

\section{Discussion}

According to WHO, non-endemic areas for LF are those areas where surveys have shown an infection rate of less than $1 \%$ [13]. The overall LF prevalence estimated in NC was $0.62 \%$ (CI 95\% [0.60-0.63]), which allows us to classify NC as a non-endemic PICTs for LF, according to WHO criteria.

Table 1 Clinical and laboratory findings for the 7 antigenemic patients

\begin{tabular}{|c|c|c|c|c|c|c|c|}
\hline Patients & 1 & 2 & 3 & 4 & 5 & 6 & 7 \\
\hline age & 64 & 62 & 34 & 28 & 35 & 31 & 47 \\
\hline $\operatorname{sex}$ & $M$ & $F$ & $M$ & $\mathrm{~F}$ & $\mathrm{~F}$ & $M$ & $\mathrm{~F}$ \\
\hline Community & Melanesian & European & Metis & European & Melanesian & Metis & European \\
\hline Birthplace & $\mathrm{NC}$ & $\mathrm{NC}$ & $\mathrm{NC}$ & $\mathrm{NC}$ & $\mathrm{NC}$ & $\mathrm{NC}$ & France \\
\hline NC arrival date & & & & & & & 1991 \\
\hline \multicolumn{8}{|l|}{ Laboratory results } \\
\hline $\mathrm{ICT}$ & Positive & Positive & Positive & Positive & Positive & Positive & Positive \\
\hline Microfilaremia & Negative & Negative & Negative & Negative & Negative & Negative & Negative \\
\hline LF PCR & Negative & Negative & Negative & Negative & Negative & Negative & Negative \\
\hline Lived/worked in LF area known in $\mathrm{NC}^{*}$ & Yes & Yes & Yes & No & Yes & No & Yes \\
\hline \multicolumn{8}{|l|}{ Travels in LF endemic countries } \\
\hline Travel 1 & & Malaisia & Vanuatu & & & Vanuatu & Vanuatu (x3) \\
\hline Year & & 1988 & 2011 & & & 1994 & 1994, 1998, 2010 \\
\hline Travel 2 & & Vanuatu (x3) & & & & Indonesia & French Polynesia (x10) \\
\hline Year & & 2004, 2005, 2007 & & & & 1996 & $1992->2011$ \\
\hline Travel 3 & & & & & & Viet-Nam & Sri Lanka \\
\hline Year & & & & & & 2008 & 1990 \\
\hline
\end{tabular}

*Ouvea Island, Koumac, Canala, Ouegoa, Pouebo. Never left the territory. Visited only non-endemic countries. 
Out of the 1,035 patients included in this study, only 7 tested positive for LF antigenemia.

Patients 2, 3, 6 and 7 reported having travelled in the past to LF endemic PICTs or countries (principally Vanuatu and FP) where they may have been contaminated. Vanuatu was one of the first PICTs to initiate the GPELF; after two MDA campaigns LF antigenic prevalence in sentinel sites was $8 \%$ in 2002 [20]. FP is another PICTs that has a high LF endemic area. Despite eight rounds of MDA from 2000 to 2007 , the overall prevalence was $11.3 \%$ in 2008 [10]. The main drawback of LF antigenic detection is that it can remain positive years after the infection because adult LF worms, once dead, release substances detected by the CFA test [21].

Patients 1 and 5 had never left NC and patient 4 had only travelled in non-endemic areas. For them it is not possible to say whether or not they were infected in $\mathrm{NC}$ or if the positive result of the antigenemia was a false positive. The occurrence of false positive results in our study is to be considered because the predictive positive value of a test decreases when the prevalence of the disease in the studied population is low.

Patient 5 was born and had lived 29 years on Ouvea Island and may have been contaminated during those years. A study conducted in 1996 in this island showed that 3.7\% of the 382 adults tested were microfilaremic [11].

Patients 1,2,3,5,7 had worked or lived in the northern part of NC (Koumac, Ouegoa, Pouebo) or on East Coast (Canala), where filariasis cases have been reported according to a study conducted in 1979-1980 [12].

The seven antigenemic patients were asymptomatic, tested negative for microfilairemia and filarial DNA, and they received preventive treatment, then, no follow protocol has been implemented.

\section{Conclusion}

In view of the results, we conclude that the LF prevalence in $\mathrm{NC}$ is less than $1 \%$, so we assume that LF is not a public health concern in NC and that there is no need to set up the GPELF. Nevertheless, as the overall population has not been tested and as three patients had never been exposed in endemic areas, we cannot conclude that $\mathrm{NC}$ is totally free of LF, especially in some very remotes areas. To our knowledge, Aedes vigilax is the potential vector of LF in NC [12], Ae. polynesiensis, the main vector of LF in the Pacific is not present in NC, suggesting that the potential for filariasis emergence is low in this country.

\section{Abbreviations}

CFA: Circulating filarial antigens; Cl: Confidence interval; DNA: Deoxyribonucleic acid; FP: French polynesia; GPs: General practitioners; GPELF: Global Programme to Eliminate Lymphatic Filariasis;

ICT: Immunochromatographic test; LF: Lymphatic filariasis; MDA: Mass Drug Administration; NC: New Caledonia; PacELF: Pacific Programme to Eliminate
Lymphatic Filariasis; PICTs: Pacific Island Countries and Territories; PCR: Polymerase chain reaction; WHO: World Health Organization.

\section{Competing interests}

All authors declare that no commercial or other association that might pose a competing interest exists.

\section{Authors' contributions}

$M D, J C, J P G, D M$ wrote the protocol and defined the study design. AF, FR carried out patients investigations and MD conducted the statistical analyzes. $M D, J C, A F, F R, J P G, D M$ drafted parts of the manuscript. All of the authors have approved the content of the manuscript.

\section{Acknowledgements}

We are grateful to all the hospitals, medical centers, GPs and people who participated in this study. We thank Dr Xavier Deparis and the team of the French Army's Epidemiology and Public Health Center for their assistance during the finalization of the protocol, and the Institute Pasteur of New Caledonia and the Koumac Hospital for their microscopic filarial detection. We also thank Dr Michèle John for her proofreading and wise remarks and Laurent Guillaumot for his valuable advices about entomology. Finally, we thank Mrs Sheryl Mellor from the Secretariat of the Pacific Community for her help in English translation.

\section{Author details}

${ }^{1}$ Health Action Service, New Caledonia Health Department, BP N4 - 98851 Nouméa cédex, New Caledonia. ${ }^{2}$ Institut Louis Malarde Institut, Tahiti, French Polynesia.

Received: 13 October 2014 Accepted: 4 February 2015

Published online: 15 February 2015

\section{References}

1. Nanduri J, Kazura JW. Clinical and laboratory aspects of filariasis. Clin Microbiol Rev. 1989;2(1):39. doi:10.1128/CMR.2.1.39.

2. Burkot TR, Durrheim DN, Melrose WD, Speare R, Ichimori K. The argument for integrating vector control with multiple drug administration campaigns to ensure elimination of lymphatic filariasis. Filaria J. 2006;5:10.

3. Huppatz C, Capuano C, Palmer K, Kelly PM, Durrheim DN. Lessons from the Pacific programme to eliminate lymphatic filariasis: a case study of 5 countries. BMC Infect Dis. 2009 Jun 12. doi:10.1186/1471-2334-9-92.

4. Krishna KA, Harichandrakumar KT, Das LK, Krishnamoorthy K. Physical and psychosocial burden due to lymphatic filariasis as perceived by patients and medical experts. Trop Med Int Health. 2005;10(6):567-73.

5. Wijesinghe RS, Wickremasinghe AR, Ekanayake S, Perera MS. Physical disability and psychosocial impact due to chronic filarial lymphoedema in Sri Lanka. Filaria J. 2007:6:4.

6. World Health Organization. Preparing and Implementing a National Plan to Eliminate Lymphatic Filariasis. Geneva, Switzerland: WHO/CDS/CPE/CEE/ 200015; 2000.

7. WHO WPR. The PacELF Way: towards the elimination of lymphatic filariasis from the Pacific, 1999-2005. Geneva, Switzerland: World Health Organization Publications; 2006

8. Ichimori K, Crump A. Pacific collaboration to eliminate lymphatic filariasis. Trends Parasitol. 2005;21(10):441-4. Review.

9. Guillaumot L. Arboviruses and their vectors in the Pacific-status report. Pac Health Dialog. 2005;12(2):45-52.

10. Mou Y, Plichart C, Legrand AM, Mallet HP, Cerf N, Nguyen LN. Assessment of the prevalence of lymphatic filariasis in French Polynesia in 2008. French: BEH thématique 48-49-50 / 22 décembre; 2009.

11. Monchy D, Barny S, Rougier Y, Baudet JM, Gentile B. Survey of lymphatic filariasis on Ouvea Island in New Caledonia. Med Trop (Mars). 1999;59(2):146-50. French.

12. Le Godinec G, Fauran P. Survey on filariasis in New Caledonia. Bull Soc Pathol Exot Filiales. 1984;77:344-51. French.

13. WHO. Monitoring and epidemiological assessment of the programme to eliminate lymphatic filariasis at implantation unit level. World Health Organization 2005. WHO/CDS/CPE/CEE/2005.50.

14. Bouyer J, Hemon D, Cordier S, Derriennic F, Stücker I, Stengel B, et al. Epidémiologie Principes et méthodes quantitatives. Edition INSERM, Paris (1995). French 
15. Vierron E, Giraudeau B. Design effect in multicenter studies: gain or loss of power? BMC Med Res Methodol. 2009;9:39. doi:10.1186/1471-2288-9-39.

16. Simonsen PE, Magesa SM. Observations on false positive reactions in the rapid NOW Filariasis card test. Trop Med Int Health. 2004;9:1200-2.

17. Rao RU, Atkinson LJ, Ramzy RM, Helmy H, Farid HA, Bockarie MJ, et al. A real-time PCR-based assay for detection of Wuchereria bancrofti DNA in blood and mosquitoes. Am J Trop Med Hyg. 2006;74:826-32.

18. Plichart C, Lemoine A. Monitoring and evaluation of lymphatic filariasis interventions: an improved PCR-based pool screening method for high throughput Wuchereria bancrofti detection using dried blood spots. Parasit Vectors. 2013;6:110. doi:10.1186/1756-3305-6-110.

19. WHO. Progress report 2000-2009 and strategic plan 2010-2020 of the global programme to eliminate lymphatic filariasis: halfway towards eliminating lymphatic filariasis. World Health Organization 2010. WHO/HTM/ NTD/PCT/2010.6.

20. Fraser M, Taleo G, Taleo F, Yaviong J, Amos M, Babu M, et al. Evaluation of the program to eliminate lymphatic filariasis in Vanuatu following two years of mass drug administration implementation: results and methodologic approach. Am J Trop Med Hyg. 2005;73(4):753-8.

21. Malla N, Elango A, Pani SP, Mahajan RC. Kinetics of microfilaraemia \& antigenaemia status by $\mathrm{Og}(4) \mathrm{C}(3)$ ELISA in bancroftian filariasis. Indian J Med Res. 2007;126:567-74.

\section{Submit your next manuscript to BioMed Central and take full advantage of:}

- Convenient online submission

- Thorough peer review

- No space constraints or color figure charges

- Immediate publication on acceptance

- Inclusion in PubMed, CAS, Scopus and Google Scholar

- Research which is freely available for redistribution 